\title{
Early Results of Combined and Staged Coronary Bypass and Carotid Endarterectomy in Advanced Age Patients in Single Centre
}

\author{
Hikmet Iyem ${ }^{1, *}$ and Suat Buket ${ }^{2}$ \\ ${ }^{I}$ Dicle University, Department of Cardiovascular Surgery, Diyarbakir, Turkey \\ ${ }^{2}$ Kent Hospital, Department of Cardiovascular Surgery, Izmir, Turkey
}

\begin{abstract}
Absract: Aim: In present study, we aimed to compare the staged and combined surgery in patients with severe carotid stenosis and coronary atherosclerosis and detect the factors affecting mortality and morbidity.

Material and method: Between 2004 and 2008, 120 patients with predominant ischemic heart disease were enrolled to study. Patients were divided into three groups on basis surgery procedure. Group $1(n=40)$ includeed patients had coronary artery disease without carotid disease underwent coronary artery by-pass graft (CABG) operation. Group 2 ( $n=40)$ : included patients underwent combined surgery procedure including CABG and carotid endarterectomy (CEA). Patients underwent staged CABG and CEA were enrolled to Group $3(n=40)$. All patients were in advanced aged and were had the same risk factors atributable atherosclerosis

Results: Mean age of the patients in all groups were $68 \pm 6,69 \pm 3,71 \pm 2$ respectively, and $83 \%$ were male. Eight patients died in all groups at follow-up(seven in group 2 and 3, and one in group 1) and the difference between both groups was statistically significant $(\mathrm{p}<0.001)$. The follow-up period in the intensive care unit, and hospitalization period were not statistically different between $\mathrm{CABG}$ group and combined CEA plus $\mathrm{CABG}$ group.

Conclusion: We think that the results of staged or combined CABG plus CEA surgery are satisfactory in patients with severe carotid disease and advanced coronary artery disease. However, the mortality and morbidity in both procedures are higher than those of alone.
\end{abstract}

\section{INTRODUCTION}

Cardiovascular diseases are the most cause of death in the developed countries. Modeling studies in many developed countries, particularly the United States, Netherlands, New Zealand, and United Kingdom, suggest that 55\% to $65 \%$ of recent, substantial CHD mortality declines can be attributed to declines in major risk factors, the remainder being attributable to medical and surgical treatments [1]. In the USA $39.4 \%$ of all of deaths is due to cardiovascular diseases and coronary heart diseases account for the the biggest part (54\%) of cardiovascular disease leading death of cardiovascular diseases. In addition, $18 \%$ of cardiovascular caused deaths is due to stroke [2]. Postoperatif neurological problem is one of the serious complication of cardiac surgery. Frequency of serious perioperative neurological complication among patients undergoing coronary artery bypass surgery has been determined in range of $0.5 \%-7 \%$ [2-4]. The possible mechanisms of neurological complication seen after elective CABG surgery are decrease in the brain blood flow due to hypotension or hypoperfusion, macro or micro embolisation and intracranial or extracranial vascular disease cause cerebrovascular event [5]. Although carotid arterial stenosis is seen in $2.4 \%-14 \%$ of patients with coronary artery disease undergoing $\mathrm{CABG}$; coronary artery disease is seen

*Address correspondence to this author at the Dicle Universitesi, Tip Fakultesi Kalp Damar Cerrahisi AD, Diyarbakir, Turkey; Tel: +90 412248 80 01; Fax: +90 41224880 12; E-mail: hikmetiyem@gmail.com in $40 \%-50 \%$ of patients undergoing carotid endarterektomy (CEA) [6-9]. Berens et al. 1 reported that stroke was seen by rate of $10.9 \%$ in $>65$ years old patients with $>80 \%$ carotid arterial stenosis [10]. The frequency of perioperative myocardial enfarction in patients underwent isolated CEA has been determined in range of $1.5 \%$ to 5\% [11]. CEA is recommended in patients with symptomatic carotid disease undergoing CABG due to coronary artery disease, but it is not well determined which procedure including staged or combined CEA plus CABG should be performed in current literature. The mechanism for stroke in patients with asymptomatic serious carotid stenosis undergoing $\mathrm{CABG}$ is still controversial [12]. In present study, we aimed to compare the staged and combined surgery in patients with severe carotid stenosis and coronary atherosclerosis and detect the factors affecting mortality and morbidity.

\section{MATERIALS AND METHOD}

Between May 2004 and February 2008, 120 patients with predominant ischemic heart disease were enrolled to study. Group $1(\mathrm{n}=40)$ includeed patients had coronary artery disease without carotid disease underwent coronary artery bypass graft $(\mathrm{CABG})$ operation. Group $2(\mathrm{n}=40)$ : included patients underwent combined surgery procedure including CABG and carotid endarterectomy (CEA). Patients underwent staged $\mathrm{CABG}$ and CEA were enrolled to Group 3 $(n=40)$. The approval of the ethical commitee of our hospital and informed concent from all patients were taken. All patients were in advanced aged and were had the same risk 
factors atributable atherosclerosis. All groups were compared in terms of preoperative risk factors, operative technique, preoperative and postoperative morbidity, mortality, and the factors affecting this parameters.

\section{Preoperative Evaluation}

$58.9 \%$ of patients has been expiriencing chronical angina pectoris which is in the class II-III accarding to Canadian classification. Eighteen patients in the group 2, and 16 patients in group 3 were neurologically asymptomatic. Firstly, coloured dupplex ultrasonografy, and then carotid digital substraction anjiografy were performed to all patients undergoing CEA. In 5 patients Type A ulcerated lesion was found by Dupplex ultrasonografy, and in remain $>70 \%$ carotid stenosis was found (Table 1).

Table 1. Distribution of Carotid Lesions

\begin{tabular}{|l|l|}
\hline & Number of Patients \\
\hline \hline Bilateral \%50-70 & $1^{*}$ \\
\hline Unilateral \%50-70 & $4^{*}$ \\
\hline Bilateral right or left side $>\% 70$ & 3 \\
\hline Unilateral or bilateral $<\% 50$ & - \\
\hline Unilateral $>\% 70$ & 71 \\
\hline Bilateral $>\% 70$ & 1 \\
\hline
\end{tabular}

\section{Anesthesia and Surgical Technique}

Coronary revascularization and CEA procedures were performed in all patients in simultaneous fashion under general anesthesia. The same surgeons and operative team performed all procedures. Routine CABG and CEA protocol of our cardiovascular surgery clinic was applied to all patients. Anesthesia was induced with $20 \mathrm{mcg} / \mathrm{kg}$ fentanyl citrate, $0.12 \mathrm{mg} / \mathrm{kg}$ pancuronium, $2 \mathrm{mg} / \mathrm{kg}$ propofol. After tracheal intubation, mechanical ventilation was institued with 6-8 $\mathrm{ml} / \mathrm{kg}$ tidal volume and $10-12 / \mathrm{min}$ respiratory rates. Anesthesia was maintained with $10 \mathrm{mcg} / \mathrm{kg}$ of fentanyl and 1 $\mathrm{mg} / \mathrm{kg}$ propofol as infusion. $2 \mathrm{mg}$ of pancuronium were given every 45 minutes throughout the operation. Five electroencephalographic (EEG) leads were placed and EEGS were monitored continuously with a Life Scan brain activity monitor (Diatek Patient Management System, Inc., SanDiego, CA). In all patients CEAs were performed prior to sternotomy. In case of bilateral internal carotid artery lesions, we performed CEA on the side with the higher degree lesion, the side related to neurological symptoms, or the dominant hemisphere. CEA was not performed in patients had totally occluded carotid vessels. Saphenous vein grafts were prepared during CEA. A standard oblique cervical incision was made. After isolation of the common, internal, and external carotid arteries, $2 \mathrm{ml}$ of heparin was administered. Vessels were clamped and an arteriotomy was created in the common carotid artery and extended into the internal carotid artery. Changes in the electroencephalogram pattern after cross clamping not leading to an increase in the mean arterial pressure were considered indications for intraluminal shunting. Intraluminal carotid shunt was not needed in any patient. The artery was opened beyond the distal extent of the plaque. The plaque was removed in the standard fashion. If the artery was thought to be small, the arteriotomy was closed with a saphenous vein patch. After completion of the CEA, the neck incision was left open until heparin reversal after $\mathrm{CPB}$. After performing CEA, CPB was instituted with standard techniques. Aortic and two stage venous canulla were used to institute the CPB using a roller pump, membrane oxygenation and identical priming solution. Systemic blood flow was maintained at 2.2-2.4 $\mathrm{L} / \mathrm{m}^{2}$, mean arterial blood pressure at $60-70 \mathrm{~mm} \mathrm{Hg}$ during $\mathrm{CPB}$. Systemic hypothermia $\left(28^{\circ} \mathrm{C}\right)$ and hemodilution were applied. Distal anastomoses were done during the cross clamp (CC) period. Proximal anastomoses were done with partial occluding clamp in beating heart. The left anterior descending artery in all patients anatomosed with left internal mammarian artery flaps. The other vessels anastomosed with greater saphenous vein grafts. Postoperatively pharmacological support was instituted according to haemodynamic situation. The pericardial (No:28) and mediastinal (No:32) chest tubes were inserted to all patients.

In group 3 including patients undergoing staged surgery, CEA was performed firstly, and CABG was performed two days later. However, both surgery were performed at same time without delaying in unstable patients.

\section{Statistical Analysis}

Statistical analysis was performed with SPSS software version 10.0 (SPSS Inc, Chicago, III). Clinical data were expressed as mean values \pm standard deviation, percents. Differences between the groups were investigated by Levine test, Bonferroni corrected t-test and Chi- Square test. Both groups and parameters inside each groups were compared using nonparametric Wilcoxon Signed Ranks test (two tailed). We investigated the effects of the variables by calculating odds ratios in univariate analyses for all patients. Differences were considered as significant if $\mathrm{p}$ value $<0.05$. Univariate analyses of demographics and variables to identify potential stroke risk factors was performed by the student's t test, Wilcoxon Signed Ranks test or the $X^{2}$ test. Multivariate determinants of the stroke were obtained by the stepwise multivariate logistic regresyon analysis. Candidate variables with a value of $\mathrm{p} \leq 0.20$ were entered into a logistic model. Regression coefficiencies that are significantly different from $1.00(\mathrm{p} \leq 0.05)$ in the completed model are considered associated with stroke. Odds rations and 95\% confidence limits as well as probability values, are reported.

\section{RESULTS}

Mean age of the patients in all groups were $68 \pm 6,69 \pm 3$, $71 \pm 2$ respectively, and $83 \%$ were male. Demographical variables such as age, sex, and preoperative risk factors in groups were given on Table 2. Among the preoperative risk factors, having diabetes mellitus, systemic hypertension, hyperlipidemia, unstable angina pectoris, left main coronary arterial disease, cerebrovascular event and chronic obstructive pulmonary disease were significantly higher in combined (group 2) or staged (group 3) CABG plus CEA groups compared only CABG group (group 1) (Table 2 ).

In 5 patients unilateral CEA plus CABG and in 75 patients bilateral CEA plus CABG were performed. The mor- 
Table 2. Demographics and Preoperative Factors of the Patients

\begin{tabular}{|c|c|c|c|c|}
\hline & Only CABG & Combined CEA+ CABG & Staged CEA+CABG & P Value \\
\hline Number of patients & 40 & 40 & 40 & - \\
\hline Male & $31(\% 77.5)$ & $32(\% 80.0)$ & $34(\% 85.0)$ & $\mathrm{a}=\mathrm{ns}, \mathrm{b}=\mathrm{ns}, \mathrm{c}=\mathrm{ns}$ \\
\hline Female & $9(\% 22.5)$ & $8(\% 20.0)$ & $6(\% 15.0)$ & $\mathrm{a}=\mathrm{ns}, \mathrm{b}=\mathrm{ns}, \mathrm{c}=\mathrm{ns}$ \\
\hline Diabetes mellitus & $25(\% 62.5)$ & $34(\% 85.0)$ & $36(\% 90.0)$ & $\mathrm{a}<0.05, \mathrm{~b}<0.05, \mathrm{c}=\mathrm{ns}$ \\
\hline Hypertension & $26(\% 65.0)$ & $33(\% 82.5)$ & $32(\% 80.0)$ & $\mathrm{a}<0.05, \mathrm{~b}<0.05, \mathrm{c}=\mathrm{ns}$ \\
\hline Hyperlipidemia & $25(\% 62.5)$ & $34(\% 85.0)$ & $31(\% 77.5)$ & $\mathrm{a}<0.05, \mathrm{~b}<0.05, \mathrm{c}=\mathrm{ns}$ \\
\hline Smoking & $32(\% 80)$ & $37(\% 92.5)$ & $38(\% 95.0)$ & $\mathrm{a}=\mathrm{ns}, \mathrm{b}=\mathrm{ns}, \mathrm{c}=\mathrm{ns}$ \\
\hline Peripheral vascular disease & $1(\% 2.5)$ & $2(\% 5.0)$ & $1(\% 2.5)$ & $\mathrm{a}=\mathrm{ns}, \mathrm{b}=\mathrm{ns}, \mathrm{c}=\mathrm{ns}$ \\
\hline COPD & $12(\% 30.0)$ & $21(\% 52.5)$ & $24(\% 60)$ & $\mathrm{a}<0.05, \mathrm{~b}<0.05, \mathrm{c}=\mathrm{ns}$ \\
\hline Peptic/gastric ulcer & $1(\% 2.5)$ & $3(\% 7.5)$ & $2(\% 5.0)$ & $\mathrm{a}=\mathrm{ns}, \mathrm{b}=\mathrm{ns}, \mathrm{c}=\mathrm{ns}$ \\
\hline Cancer & $1(\% 2.5)$ & - & $1(\% 2.5)$ & $\mathrm{a}=\mathrm{ns}, \mathrm{b}=\mathrm{ns}, \mathrm{c}=\mathrm{ns}$ \\
\hline \multicolumn{5}{|l|}{ Cardiac Profile } \\
\hline Preoperative MI & $5(\% 12.5)$ & $7(\% 17.5)$ & $6(\% 15)$. & $\mathrm{a}=\mathrm{ns}, \mathrm{b}=\mathrm{ns}, \mathrm{c}=\mathrm{ns}$ \\
\hline Atrial fibrillation & $2(\% 5.0)$ & $1(\% 2.5)$ & $3(\% 7.5)$ & $\mathrm{a}=\mathrm{ns}, \mathrm{b}=\mathrm{ns}, \mathrm{c}=\mathrm{ns}$ \\
\hline $\operatorname{LVEF}(\%)$ & $43.1 \pm 11.3$ & $45.3 \pm 16.1$ & $47.5 \pm 9.2$ & $\mathrm{a}=\mathrm{ns}, \mathrm{b}=\mathrm{ns}, \mathrm{c}=\mathrm{ns}$ \\
\hline
\end{tabular}

COPD: Chronic obstructive pulmonary disease, BUN: Blood urea nitrogen,

LVEF: Left ventricular ejection fraction, MI: Myocardial infarction, ns: not significant,

a: $p$ value for group Only CABG versus group Combined CEA+CABG.

b: $p$ value for group Only CABG versus group Staged CEA+CABG.

c: $p$ value for group Combined CEA+ CABG versus group Staged CEA+CABG

tality was recorded in one patient due to arrythmia in group 3 and in seven patients in group 2. In this study, patchplasty was done in 12 of $80(10 \%)$ patients underwent CEA, in remain, the incision of carotid artery was closed primarily. The mean clamping time was $21.24 \pm 6.05$ (ranged 15 to 36 minutes) (Table 3).

The compared perioperative and potoperative variables in three groups were shown in Table 4. The follow-up time in the intensive care unit, and duration of hospitalization were not statistically different between $\mathrm{CABG}$ group (group 1) and CEA plus CABG groups (group 2 and 3). No case of bleeding or hematoma was recorded at incision side.

In our study mortality was occured in 8 patients (seven in group 2 and 3, and one in group 1). This difference between CABG alone and CABG plus CEA groups in term of mortalitys was statistically significant $(\mathrm{p}<=.001)$.
Table 3. Operative Variables of Carotid Endarterectomy

\begin{tabular}{|c|c|}
\hline & Patient (n=) \\
\hline \hline Unilateral carotid stenosis & $75(\% 93.75)$ \\
\hline Right carotid endarterectomy & $39(\% 48.75)$ \\
\hline Left carotid endarterectomy & $36(\% 45.0)$ \\
\hline Bilateral carotid stenosis & $5(\% 6.25)$ \\
\hline EEG monitoring & $80(\% 100)$ \\
\hline Patchplasty & $12(\% 15.0)$ \\
\hline Primary closure & $68(\% 85.0)$ \\
\hline Carotid clamping time (min) mean \pm SD & $21.24 \pm 6.05$ \\
\hline
\end{tabular}


On the univariate analysis, among the preoperative risk factors diabetes mellitus, hypertension, hyperlipidemia, chronic obstructive lung disease, history of cerebrovascular disease, left main coronary artery disease, unstable angina pectoris, and among the postoperative risk factors, stroke, reexploration due to bleeding and arrythmia were found as factors affecting on mortality (Tables 2-5). However, on multivariate analysis, among the perioperative risk factors history of serebrovascular disease, left main coronary artery disease and among the postoperative risk factors stroke were found to as factors affecting mortality with statistical significance $(\mathrm{p}=0.002, \mathrm{p}=0.032, \mathrm{p}=0.005$, respectively) (Table 6). No statistically significant difference was found when the staged and combined CEA plus CABG groups compared in terms of stroke and neurological deficit. Postoperative stroke was seen in two patients in combined CEA plus CABG group, and in three patients in staged CEA plus CABG group (Table 5).

Table 4. Operative and Postoperative Variables

\begin{tabular}{|c|c|c|c|c|}
\hline & Only CABG & Combined CEA+ CABG & Staged CEA+CABG & $P$ value \\
\hline Cross clamp time(min) & $41.2 \pm 20.9$ & $44.9 \pm 11.6$ & $42.9 \pm 14.2$ & ns \\
\hline Graft number (n) & $3.04 \pm 0.8$ & $3.1 \pm 0.7$ & $3.06 \pm 0.6$ & ns \\
\hline Perioperative MI $(\mathrm{n}=)$ & $1(\% 2.5)$ & $2(\% 5.0)$ & $1(\% 2.5)$ & ns \\
\hline Mediastinal drainage $(\mathrm{mL})$ & $639.8 \pm 36.3$ & $652 \pm 23.2$ & $625.6 \pm 17.5$ & ns \\
\hline $\operatorname{IIABP}(\mathrm{n}=)$ & $3(\% 7.5)$ & $4(\% 10.0)$ & $2(\% \% 5.0)$ & $\mathrm{ns}$ \\
\hline ICU stay (hour) & $22.7 \pm 16.7$ & $25.3 \pm 43.2$ & $27.4 \pm 43.5$ & ns \\
\hline Hospital stay (day) & $7.1 \pm 2.6$ & $7.3 \pm 8.8$ & $7.5 \pm 5.6$ & $\mathrm{~ns}$ \\
\hline
\end{tabular}

Bonferroni corrected t-test: no significant differences between groups.

CPB: Cardiopulmonary bypass ICU: Intensive care unit, MI: Myocardial infarction,

IIABP: Intraoperative intraaortic bollon pump.

ns: not significant.

a: $p$ value for group Combined $C E A+C A B G$ versus group Only CABG.

b: $p$ value for group Staged CEA+CABG versus group Only CABG

Table 5. Postoperative Complications and Factors Affecting Morbidity and Mortality

\begin{tabular}{|c|c|c|c|c|}
\hline Complications & Only CABG N= & Combined CEA+CABG N= & Staged CEA+CABG N= & $P$ value \\
\hline Acute renal failure & $2(\% 5)$ & $3(\% 7.5)$ & $4(\% 10.0)$ & $\mathrm{a}=\mathrm{ns}, \mathrm{b}=\mathrm{ns}, \mathrm{c}=\mathrm{ns}$ \\
\hline Multiple organ failure & - & - & $1(\% 2.5)$ & $\mathrm{a}=\mathrm{ns}, \mathrm{b}=\mathrm{ns}, \mathrm{c}=\mathrm{ns}$ \\
\hline Pulmonary complications & - & $4(\% 10.0)$ & $6(\% 15)$ & $\mathrm{a}<0.05, \mathrm{~b}<0.05, \mathrm{c}=\mathrm{ns}$ \\
\hline Mediastinitis & - & - & $1(\% 2.5)$ & $\mathrm{a}=\mathrm{ns}, \mathrm{b}=\mathrm{ns}, \mathrm{c}=\mathrm{ns}$ \\
\hline Transient ischemic episode & - & $3(\% 7.5)$ & $2(\% 5.0)$ & $\mathrm{a}<0.05, \mathrm{~b}<0.05, \mathrm{c}=\mathrm{ns}$ \\
\hline Transient hemiparesia & - & $2(\% 5.0)$ & $3(\% 7.5)$ & $\mathrm{a}<0.05, \mathrm{~b}<0.05, \mathrm{c}=\mathrm{ns}$ \\
\hline Permanent hemiplegia & - & $2(\% 5.0)$ & $2(\% 5.0)$ & $\mathrm{a}<0.05, \mathrm{~b}<0.05, \mathrm{c}=\mathrm{ns}$ \\
\hline Wound infection & $1(\% 2.5)$ & $1(\% 2.5)$ & $1(\% 2.5)$ & $\mathrm{a}=\mathrm{ns}, \mathrm{b}=\mathrm{ns}, \mathrm{c}=\mathrm{ns}$ \\
\hline
\end{tabular}

CEA: Carotid endarterektomy, CABG: Coronary arterial bypass greft ns: not significant,

a: $p$ value for group Only CABG versus group Combined CEA+CABG.

$\mathrm{b}$ : $\mathrm{p}$ value for group Only $\mathrm{CABG}$ versus group Staged CEA+CABG.

c: $p$ value for group Combined CEA+CABG versus group Staged CEA+CABG. 


\section{DISCUSSION}

The prevalence of significant carotid disease in the cardiac surgical population reflects the systemic nature of the atherosclerotic process. In an analysis of 1779 patients, $14.7 \%$ have $50 \%$ or greater stenosis and $6.3 \%$ have $75 \%$ or greater carotid artery stenosis. Carotid artery stenosis grater than $50 \%$, redo surgery, peripheral vascular disease, longer pump time and hypercholesterolemia were found to be independently associated with an increased risk of the stroke and mortality [13]. D'agostino, et al. [14] assessed the incidence and risk factors of stroke in 1835 patients undergoing CABG and found that corotid stenosis $>50 \%$ was a risk factor in this population. It was found that, mortality rate of combined CEA plus CABG was $2-12 \%$, and stroke rate in this group of patients was $1-15 \%$ [15-18]. When staged and combined surgeries were compared different results were given according to clinics and years. Borger et al. [19] were studied 16 different studies which are made on 844 combined and 920 staged surgeries. They found stroke rate as $6 \%$ in combined surgery and $3.2 \%$ in staged surgery. They found death rate as $4.7 \%$ in combined surgery and as $2.9 \%$ in staged surgery; and no statistically significant difference was reported in terms of these variables between two groups. However, Hamulu et al. [20] found stroke rate as $2.3 \%$ in combined surgery and as $3.0 \%$ in staged surgery; and there were no statistically significant difference in stroke rate between two groups and in addition, the death rate was found higher in combined surgery group compared staged group $(5.7 \%$ vs. $1.5 \%, \mathrm{p}<0.05)$. In present study, we found the similar results. The stroke rate was similar in both groups of combined and staged surgery (5\% vs \% $7.5 \mathrm{p}>0.05$ ). In addition, the mortality rate also was similar in both groups $(7.5 \%$ in combined and $10 \%$ in staged group $\mathrm{p}>0.05)$. These results showed that the mortality increases independently from staged or combined surgery was performed in patients undergoing CABG plus CEA. The studies evaluated the efficacy and complications seen during perioperative and postoperative terms of combined CEA plus CABG were shown on Table 7 [21-34].

The advantages of combined surgery such as shorter hospitalization period [35], lower cost [25], acceptable early mortality and morbidity [36, 37], lower stroke risk on long term period $[37,38]$ were reported. However, there are several studies reported the disadvantages of combined surgery such as higher stroke and death rates compared to staged

Table 6. Factors Affecting Mortality on Multivariate Logistic Regression Analysis

\begin{tabular}{|l|l|l|l|l|l|}
\hline & Variable Estimate & Standart Error & P Value & Odds Ratio & 95\% CI \\
\hline \hline Preoperative history of cerebrovascular disease & 0.074 & 0.033 & 0.0002 & 1.05 & $1.021-1.125$ \\
\hline Left main coronary arterial lesion & 0.772 & 0.329 & 0.038 & 2.20 & $1.012-4.241$ \\
\hline Postoperative stroke & 0.819 & 0.519 & 0.035 & 2.23 & $1.075-5.556$ \\
\hline
\end{tabular}

Table 7. The Studies on Combined CEA+CABG and Complication Rates

\begin{tabular}{|c|c|c|c|c|c|}
\hline Author & Year & Patients $(n=)$ & Mean Age (y) & Death $(\%)$ & Stroke $(\%)$ \\
\hline Pome [21] & 1991 & 52 & 61 & 0 & 5.7 \\
\hline Vermeulen [23] & 1992 & 230 & 63 & 3.5 & 3.0 \\
\hline Chang [24] & 1994 & 189 & 66 & 2.0 & 1,0 \\
\hline Daily [26] & 1996 & 100 & 68 & 4.0 & 0 \\
\hline Mackey [27] & 1996 & 100 & 68 & 8.0 & 9.0 \\
\hline Trachiotis [28] & 1997 & 88 & 68 & 3.4 & 3.4 \\
\hline Takach [29] & 1997 & 255 & 65 & 3.9 & 3.9 \\
\hline Horst [30] & 1999 & 63 & 64 & 7.9 & 0 \\
\hline Hamulu [20] & 2000 & 88 & 66 & 5.7 & 2.3 \\
\hline Dylewsky [33] & 2001 & 33 & 68 & 6.1 & 0 \\
\hline Zacharias [34] & 2002 & 189 & 69 & 2.6 & 2.6 \\
\hline Kolh [35] & 2006 & 311 & 67 & 6 & 7 \\
\hline Our study & 2007 & 40 & 69 & 7.5 & 5 \\
\hline
\end{tabular}


surgery in current literature [39]. So, the management of concurrent carotid and coronary artery disease is controversial because of lack of prospective randomized trials evaluating the advantages or disadvantages of both surgeries. In our study there were no statistically significant difference between three groups in term of folow-up time in intensive care unit and hospitalisation periods. However, mortality and morbidity were significantly lower in isolated $\mathrm{CABG}$ group compared CEA plus CABG groups [40].

Borger et al. [19] concluded that trials must be conducted by 1500 patients if we accept expected stroke and death rate as $\% 7.5$ to get enough results by randomised trials. Recently advancing techniques such as carotid angioplasty and stenting, are also alternative techniques in risky patients undergoing cardiac surgery. Timaran et al. [41] evaluated outcomes of carotid artery stenting(CAS) before CABG versus combined CEA and CABG and assessed the risk for adverse events in 27,084 cases of concurrent carotid revascularizations and CABG and found that patients undergoing CASCABG had fewer major adverse events than those undergoing CEA-CABG. CAS-CABG patients had a lower incidence of postoperative stroke (2.4\% vs $3.9 \%$ ), and combined stroke and death $(6.9 \%$ vs. $8.6 \%)$ than the combined CEA-CABG group $(\mathrm{P}<.001)$, although in-hospital death rates were similar $(5.2 \%$ vs $5.4 \%)$ and finally they concluded that CAS might provide a safer carotid revascularization option for patients who require $\mathrm{CABG}$.

In a study reported by Hertzer, et al. [42] 129 unstable coronary bypass patients with unilateral, asymptomatic carotid lesions were prospectively randomized to receive either combined operations or CABG alone followed by delayed endarterectomy. The risk of stroke was $2.8 \%$ for the combined operations, whereas that for patients in whom delayed CEA was performed within 2 weeks was $14.4 \%$ (6.9\% at the time of coronary grafting and $7.5 \%$ at the time of delayed carotid operation). Brenner, et al. [43] examined the issue of combined and staged CABG / CEA. They demonstrated that staged procedures may result in a higher risk of myocardial infarction, particularly in the perioperative period of the carotid operation, with no difference in stroke rates. Indeed they found a very high incidence of stroke in patients undergoing such "reverse-staged" procedures.

If the combined procedure does indeed result in a higher risk of stroke or death, there are several possible reasons. One reason may be that the combined procedures are more technically difficult, from both a surgical and an anesthetical point of view, resulting in more perioperative complications. Another reason may be that combined operations result in excessive stress on the cardiovascular and cerebrovascular systems, resulting in large fluctuations in patient hemodynamics during relatively long operative procedures.

\section{CONCLUSION}

We think that the results of staged or combined CABG plus CEA surgery are satisfactory in patients with severe carotid disease and advanced coronary artery disease. However, the mortality and morbidity in both procedures are higher than those of alone.

\section{REFERENCES}

[1] Critchley J, Liu J, Zhao D, Wei W, Capewell S. Explaining the increase in coronary heart disease mortality in Beijing between 1984 and 1999. Circulation 2004; 110: 1236-44.

[2] American Heart Assosiation. Heart Disease and Stroke statistics2003 Update, Dallas, Texas; 2003, Available from: http: //www. americanheart.org, Publication and resources/statics/Heart Disease and Stroke Statistics 2003 Update.

[3] Karchtner MM, McRae LP. Carotid occlusive disease as a risk factor in major cardiovascular surgery. Arch Surg 1982; 117: 1086-8.

[4] Egloff L, Laske A, Siebemann R, Studer M, Keller H. Cerebral insult in heart surgery. Schweiz Med Wochenschr 1996; 126: 47782.

[5] Rodewald G, Dahme B, Emskötter T, et al. Central nervous system risk factors in heart surgery. Z Kardiol 1990; 79: 13-21.

[6] Minami K, Fukahara K, Boethig D, Bairaktaris A, Fritzsche D, Koerfer R. Long-term results of simultaneous carotid endarterectomy and myocardial revascularization with cardiopulmonary bypass used for both procedures. J Thorac Cardiovasc Surg 2000; 119: 764-73.

[7] Bull DA, Neumayer LA, Hunter GC, et al. Risk factors for stroke in patients undergoing coronary artery bypass grafting. Cardiovasc Surg 1993; 1: 182-5.

[8] Ricotta JJ, Faggioli GL, Castilone A, Hassett JM. Risk factors for stroke after cardiac surgery. Buffalo Cardiac Cerebral Study Group. J Vasc Surg 1995; 21: 359-63.

[9] Urbinati S, Di Pasquale G, Andreoli A, et al. Preoperative noninvasive coronary risk stratification in candidates for carotid endarterectomy. Stroke 1994; 25: 2022-7.

[10] Jones EL, Craver JM, Michalik RA, et al. Combined carotid and coronary operations: When are they necessary? J Thorac Cardiovasc Surg 1984; 87: 7-16.

[11] Yeager R, Moneta R. Assessing the cardiac risk in vascular surgical patients: Current state. Perspect Vasc Surg Endovasc Ther 1989; 2: $18-36$.

[12] Murdock DK, Rengel LR, Schlund A, et al. Stroke and atrial fibrillation following cardiac surgery. WMJ 2003; 102: 26-30.

[13] Rictta JJ, Faggioli GL, Castilone A, Hassett JM. Risk factors of stroke after cardiac surgery: Buffalo Cardiac-Cerebral Study Group. J Vasc Surg 1995; 21: 359-63.

[14] D'Agostino RS, Svensson LG, Neumann DJ, Balkhy HH, Williamson WA, Shahian DM. Screening carotid ultrasonography and risk factors for stroke in coronary artery surgery patients. Ann Thorac Surg 1996; 62: 1714-23.

[15] Birncioglu CL, Beyazit M, Ulus AT, Bardakcı H, Kucuker SA, Tasdemir O. Carotid disease is a risk factor for stroke in coronary bypass operations. J Card surg 1999; 14: 417-23.

[16] Jones EL, Craver JM, Michalik RA, et al. Combined carotid and coronary operations: When are they necessary? J Thorac Cardiovasc Surg 1984; 87: 7-16.

[17] Hertzer NR, O'Hara PJ, Mascha EJ, Krajewski LP, Sullivan TM, Beven EG. Early outcome assessment for 2228 consecutive carotid endarterectomy procedures: The Clevland Clinic experience from 1989 to 1995 . J Vasc Surg 1997; 26: 1-10.

[18] Akins CW. Combined carotid endarterectomy and coronary revascularization operation. Ann Thorac Surg 1998; 66: 1483-94.

[19] Borger MA, Fremes SE, Weisel RD, et al. Coronary bypass and carotid endarterectomy: Does increase risk? A metaanalysis. Ann Thorac Surg 1999; 68: 14-21.

[20] Hamulu A, Yagdi T, Atay Y, Buket S, Calkavur T, Iyem H. Coronary artery bypass and carotid endarterectomy: combined approach. Jpn Heart J 2001; 42: 539-52.

[21] Pomè G, Passini L, Colucci V, et al. Combined surgical approach to coexistent carotid and coronary artery disease. J Cardiovasc Surg 1991; 32: 757-93.

[22] Rizzo RJ, Whittemore AD, Couper GS, et al. Combined carotid and coronary revascularization: the preferred approach to the severe vasculopath. Ann Thorac Surg 1992; 54: 1099-109

[23] Vermeulen FE, Hamerlijnck RP, Defauw JJ, Ernst SM. Synchronous operation for ischemic cardiac and cerebrovascular disease. Ann Thorac Surg 1992; 53: 381-90.

[24] Chang BB, Darling RC III, Shah DM, Paty PS, Leather RP. Carotid endarterectomy can be safely performed with acceptable mortality and morbidity in patients requiring coronary artery bypass grafts. Am J Surg 1994; 158: 94-6. 
[25] Akins CW, Moncure AC, Daggett WM. Safety and efficacy of concomitant carotid and coronary artery operations. Ann Thorac Surg 1995; 60: 311-7.

[26] Daily PO, Freeman RK, Dembitsky WP, et al. Cost reduction by combined carotid endarterectomy and coronary artery bypass grafting. J Thorac Cardiovasc Surg 1996; 111: 185-93.

[27] Mackey WC, Khabbaz K, Bojar R, O'Donnell TF. Simultaneous carotid endarterectomy and coronary artery bypass: perioperative risk and long-term survival. J Vasc Surg 1996; 24: 58-64.

[28] Trachiotis GD, Pfister AJ. Management strategy for simultaneous carotid endarterectomy and coronary revascularization. Ann Thorac Surg 1997; 64(4): 1013-8.

[29] Takach TJ, Reul GJ Jr, Cooley DA, et al. Is an integrated approach warranted for concomitant carotid and coronary artery disease? Ann Thorac Surg 1997; 64(1): 816-22.

[30] Horst M, Geissler HJ, Mehlhorn U, et al. Simultaneous carotid and coronary artery surgery: Indications and perioperative outcome. Thorac Cardiovasc Surg 1999; 47: 328-832.

[31] Plestis KA, Ke S, Jiang ZD, Howell JF. Combined carotid endarterectomy and coronary artery bypass: immediate and long-term results. Ann Vasc Surg 1999; 13: 84-92.

[32] Gott JP, Thourani VH, Wright CE, et al. Risk neutralization in cardiac operations: detection and treatment of associated carotid disease. Ann Thorac Surg 1999; 68: 850-7.

[33] Dylewski M, Canver CC, Chanda J, Darling RC $3^{\text {rd }}$, Shah DM. Coronary artery bypass combined with bilateral carotid endarterectomy. Ann Thorac Surg 2001; 71: 777-81; discussion 781-92.

[34] Zacharias A, Schwann TA, Riordan CJ, et al. Operative and 5-year outcomes of combined carotid and coronary revascularization: review of a large contemporary experience. Ann Thorac Surg 2002; 73: 491-7; discussion 497-508.
[35] Kolh PH, Comte L, Tchana-Sato V, et al. Concurrent coronary and carotid artery surgery: factors influencing perioperative outcome and long-term results. Eur Heart J 2006; 27: 49-56.

[36] Brow TD, Kakkar VV, Pepper JR, Das SK. Toward a rational management of concomitant carotid and coronary artery disease. J Cardiovasc Surg (Torino) 1999; 40: 837-44.

[37] Gaudino M, Glieca F, Alessandrini F, et al. Individualized surgical strategy for the reduction of stroke in patients undergoing CABG. Ann Thorac Surg 1999; 67: 1246-53.

[38] Plestis KA, Ke S, Jiang ZD, Howell JF. Combined carotid endarterectomy and coronary artery bypass: Immediate and long-term results. Ann Vasc Surg 1999; 13: 84-92.

[39] Kaul TK, Fields BL, Riggins LS, Wyatt DA, Jones CR. Coexistent coronary and cerebrovascular disease: Results of simultaneous surgical management in specific patient groups. Cardiovasc Surg 2000; 8: 355-65.

[40] Khaitan L, Sutter FP, Goldman SM, et al. Simultaneous carotid endarterectomy and coronary revascularization. Ann Thorac Surg 2000; 69: 421-4.

[41] Timaran CH, Rosero EB, Smith ST, Valentine RJ, Modrall JG, Clagett GP. Trends and outcomes of concurrent carotid revascularization and coronary bypass. J Vasc Surg 2008; 48: 355-60.

[42] Hertzer NR, Loop FD, Beven BG. Surgical staging for simultaneous coronary and carotid disease: a study including prospective randomization. J Vasc Surg 1989; 9: 455-63.

[43] Brenner BJ, Hermans H, Eisenbud D. The management of patients requiring coronary bypass and carotid endarterectomy. Surgery for cerebrovascular disease. WB Saunders: Philadelphia 1996; pp. 280287. 